Results and evaluation Attendance was 31/32. 59\% had 12 months or less experience as a registrar. $66 \%$ were able to perform thoracocentesis and 63\% seldinger drain independently. Most others were competent enough to perform with a colleague supervising. Additionally $38 \%$ and $25 \%$ of registrars were deemed to be able to teach other thoracocentesis and seldinger drains respectively.

Learner feedback was extremely positive and self-rated confidence and safety improved from 5-7.6 and 5.2 to 7.7 out of 10 respectively. Responses highly valued the fact this was delivered by a Consultant and identified a need for further bedside chest US training.

\section{M19 PATIENT PERSPECTIVES OF AN AMBULATORY PLEURAL SERVICE}

N Devani, U Gupta, R Kaiser, RH Johns. Barking, Havering and Redbrige University Hospitals NHS Trust, Essex, UK

\subsection{6/thoraxjnl-2016-209333.461}

Background and objectives Barking, Havering and Redbridge University Trust (BHRUT) serves a population of 750,000 patients with a large burden of pleural disease. Patients admitted and requiring pleural drainage usually results in a long length of stay of around 7-10 days. Outpatient ambulatory management of undiagnosed and known malignant pleural effusions is increasing nationally in the UK through development of pleural clinics. Previous reports have demonstrated these to be financially efficacious and avoid hospitalisation. We sought to demonstrate that they are also well received and favoured by patients.

Methods In December 2015, an outpatient weekly pleural aspiration service was established receiving referrals directly from respiratory outpatients, $A \& E$ and acute medicine. We prospectively audited patients attending this service between December 2015 and June 2016. Patients were asked to complete an in-depth questionnaire to assess their experience on the day, any procedural discomfort and attitudes toward such an outpatient service. Results 81 patients attended our service over this period. Median age was 74 (range 30-92), 40\% female. 58 patients returned a completed questionnaire. $86 \%$ of patients were seen within a week of referral with the rest waiting less than 2 weeks. The majority $(74 \%, n=43)$ of patients did not notice any deterioration in their symptoms during this wait. Median pain score was 3 (range $1-10) .78 \%(n=45)$ of patients felt they could continue with their normal activities post procedure. Only 2 patients would have preferred to undergo the procedure as an inpatient citing frailty as the reason. $98 \%(n=57)$ of patients felt that an outpatient pleural service was a good idea. 78\% $(n=45)$ rated the service as excellent, $17 \%(\mathrm{n}=10)$ as 'above average' and only $5 \%(\mathrm{n}=3)$ as 'average.'

Conclusions Outpatient management of pleural effusions is favoured by patients with most rating our service as excellent. Patients are seen promptly with the majority reporting no deterioration in their symptoms during the wait. The procedure is well tolerated and allows patients to continue with their normal daily activities. In addition to important financial benefits of reducing hospital bed-days in patients with pleural effusions, our newly established service has been shown to be beneficial in promoting a positive patient experience. HOSPITAL - 1 YEAR RETROSPECTIVE REVIEW

A Fawzi, N Maddekar, S Khan, S Bikmalla, M Iqbal, AKA Abi Musa Asa'ari, T Cusay, A Austin, C Moore, M Haris. Royal Stoke University Hospital, Stoke-on-Trent, UK

10.1136/thoraxjnl-2016-209333.462

Introduction Over the last decade, there has been a paradigm shift in the management of both pleural effusions and pneumothoraces. Specialty pleural day-case services have been established offering one-stop clinical assessment, imaging and intervention, with a view to early diagnosis, improved patient care and admission avoidance. We wished to evaluate the pleural service at a large university teaching Hospital.

Methods 650 consecutive outpatient episodes presenting to the pleural day-case clinic between January 2015 and January 2016 were reviewed. Patient characteristics, source of referral, diagnosis, interventions and outcomes were evaluated.

Results Total number of patient episodes: 650. 264 new outpatients, 322 outpatient follow-ups, 64 pleural in-reach. Male 403 (62\%), Female 247 (38\%). Referral Source: GP 151 (58\%), acute medicine unit/A\&E/other specialties 103 (38\%) and external referrals 10 (4\%).

Pleural Interventions: 27 diagnostic aspirations, 113 therapeutic aspirations, 27 chest drain insertions, 37 indwelling pleural catheters.

Indications for referrals: Pneumothorax: 24, 27 parapneumonic/Complicated effusions, 57 known malignancy, 150 unknown effusions, 8 others.

Average length of stay (based on the BTS Pleural audit 2014) ${ }^{1}$ was 8 days. Admission avoidance: 264 patients $\times 8$ days $=2,112$ bed days saved in 48 weeks. Early discharge assuming 4 days (66 patients $\times 4$ days $)=264$ bed days saved. Total bed days saved $=$ 2376 in 48 weeks - Equivalent of 7 bed days per patient.

Conclusions A dedicated pleural service has resulted in improvement in both patient outcomes and experience. The number of unnecessary pleural procedures has reduced. Complicated cases are discussed in Pleural MDT meetings. A recent patient feedback survey conducted over 2 months has shown a highly favourable patient experience of the service itself. The pleural service has allowed the department to recruit to several appropriate NIHR trials. The number of bed days saved is significant, raising the question as to whether a nationwide adoption of pleural services in the majority of trusts, would take some of the strain off of an overburdened NHS.

\section{REFERENCE}

1 Hooper CE, Welham SA, Maskell NA. Pleural procedures and patient safety: a national BTS audit of practice. Thorax 2013;70(2):189-191.

\section{M21 PLEURAL EFFUSION SIZE - A RETROSPECTIVE COMPARISON OF COMPUTED TOMOGRAPHY AND ULTRASOUND REPORTING}

MG Aldik, VM Raju, C Daneshvar. Plymouth Hospitals NHS Trust, Plymouth, UK

\subsection{6/thoraxjnl-2016-209333.463}

Background Pleural effusion size may determine patient management and is routinely reported using thoracic computed tomography (CT) and ultrasound scans. We aimed to compare agreement between these two modalities.

Methods Between August 2015 and January 2016, patients referred through the pleural service with pleural effusions were 


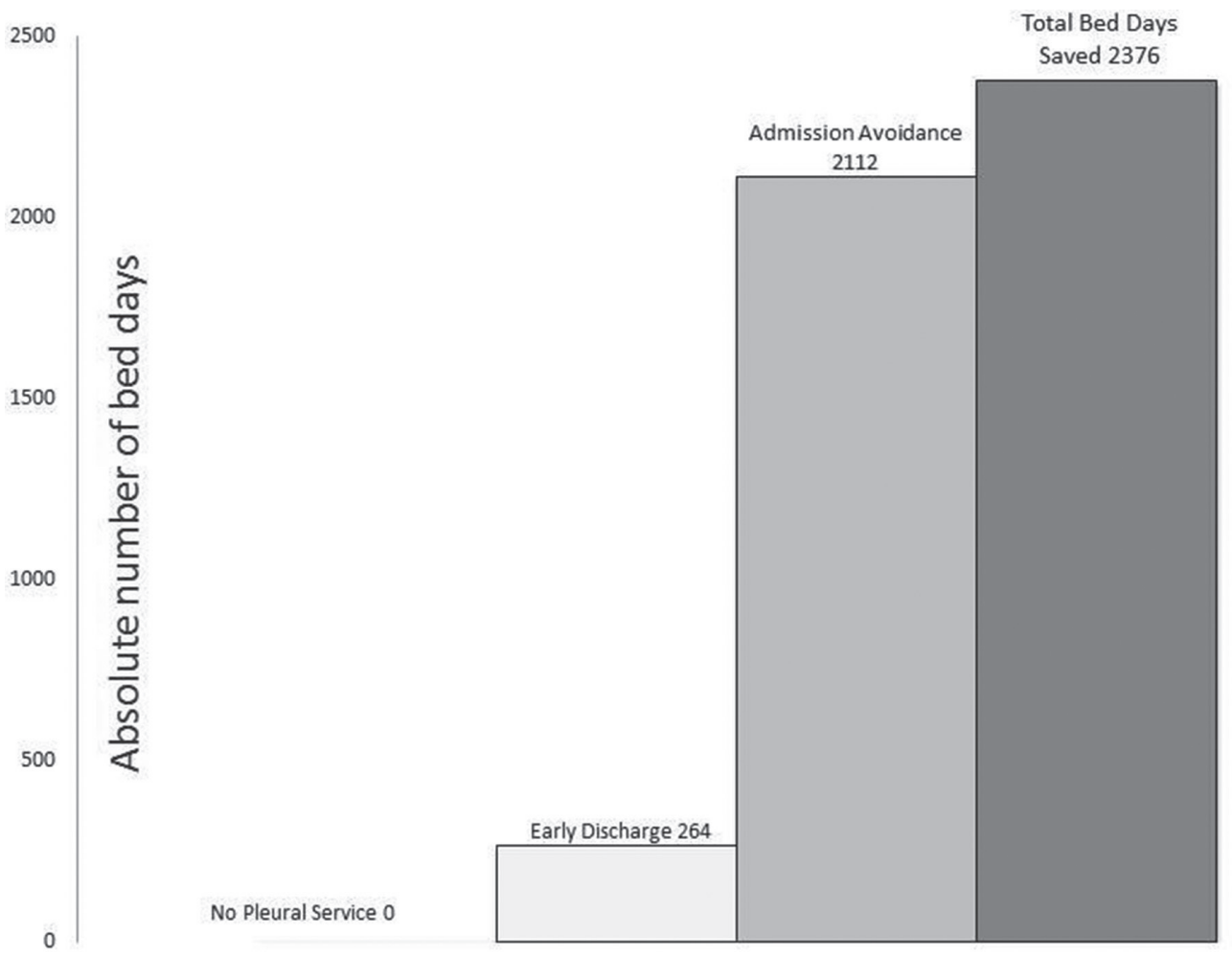

Bed days saved over a 48 week period

\section{Abstract M20 Figure 1}

included if both CT and ultrasound scans had been performed $\leq 10$ days apart with no intervening pleural procedure. Consultant radiologists reported effusions on CT as small, moderate or large. Thoracic ultrasound scans were performed by the pleural team (level 1 Royal College of Radiologists practitioners). The height of the effusion (in rib spaces) and maximal medial depth (in $\mathrm{cm}$ ) were recorded. Small, moderate and large effusions by ultrasound were defined as $\leq 1,2-3$ and $\geq 4$ rib spaces respectively. CT and ultrasound categories were compared using the Stuart-Maxwell Test.

Results In 51 patients the median age was 70 (interquartile range [IQR] 59-80) years and 26 (51\%) were male. Right effusions were dominant in $29(56 \%)$, and 48 (94\%) had a CT chest or CT pulmonary angiograms. CT scans were reported by dedicated thoracic radiologists in $13(26 \%)$ patients. CT scan reported size was available in 37 (72\%) cases, and of these, 6 (16\%), 11 (30\%) and $20(54 \%)$ were defined as small, medium and large respectively. For small, moderate and large effusions by ultrasound, the median height in rib spaces was 1.5 (IQR 1-2), 3 (IQR 2-3) and 3.5 (IQR 2.75-4) respectively. Height in rib spaces $(\mathrm{r}=0.537$, $\mathrm{p}<0.001)$ and depth of effusion $(\mathrm{r}=0.365, \mathrm{p}=0.02)$ correlated with CT reported size. However overall classification of ultrasound size was not associated with CT size ( $p=0.04)$. In 15 (40\%) effusions, the size classification differed.

Conclusions Our findings indicate that pleural effusions size determined by CT and ultrasound differed. Revised simple methodology to estimate effusion size should be sought, and may help to refine patient pathways of care. 


\section{Declarations of Interest}

\section{S34 EFFECT OF 8 AND 12 WEEKS' ONCE-DAILY TIOTROPIUM AND OLODATEROL, ALONE AND COMBINED WITH EXERCISE TRAINING, ON EXERCISE ENDURANCE DURING WALKING IN PATIENTS WITH COPD}

\subsection{6/thoraxjnl-2016-209333.464}

$\mathrm{T}$ Troosters has received grants from Innovative Medicines Initiative Joint Undertaking and speaker fees from Boehringer Ingelheim and GlaxoSmithKline.

$\mathrm{J}$ Bourbeau has received grants from the Canadian Institute of Health Research R\&D collaborative programme (AstraZeneca, Boehringer Ingelheim, GlaxoSmithKline, Merck, Nycomed, Novartis), Canadian Respiratory Research Network, Respiratory Health Network of the FRQS and Research Institute of the MUHC, and an educational grant from GlaxoSmithKline.

F Maltais has received grants from Boehringer Ingelheim, GlaxoSmithKline, AstraZeneca, Nycomed and Pfizer, personal fees from Boehringer Ingelheim, GlaxoSmithKline and Novartis, and other financial support from GlaxoSmithKline.

$\mathrm{N}$ Leidy is employed by Evidera, a health-care research firm that provides consulting and other research services to pharmaceutical and other organisations including the study sponsor.

D Erzen, D De Sousa, L Korducki and A Hamilton are employees of Boehringer Ingelheim Pharma GmbH \& Co. KG.

KL Lavoie reports personal fees from Boehringer Ingelheim for personnel training as well as a grant from AbbVie and personal fees from Bayer, Janssen, Novarits, AbbVie, Mundipharma and Almirall.

W Janssens has no conflict of interest to report.

\section{S109 TARGETING THE PROSTACYCLIN PATHWAY IN THE TREATMENT OF CONNECTIVE TISSUE DISEASE ASSOCIATED PULMONARY ARTERIAL HYPERTENSION (PAH): INSIGHTS FROM THE RANDOMISED CONTROLLED GRIPHON TRIAL WITH SELEXIPAG}

\subsection{6/thoraxjnl-2016-209333.465}

The GRIPHON study was sponsored by Actelion Pharmaceuticals Ltd.

G Coghlan: Consulting fees: Actelion Pharmaceuticals Ltd, Bayer HealthCare, GlaxoSmithKline, GenenTech, United Therapeutics. Speaker's honoraria and research grants: Actelion Pharmaceuticals Ltd, GlaxoSmithKline, Bayer HealthCare, United Therapeutics.

S Gaine: Consulting fees/honoraria: Actelion Pharmaceuticals Ltd, Bayer HealthCare, GlaxoSmithKline, United Therapeutics, Novartis, Pfizer. Steering Committee membership: Actelion Pharmaceuticals Ltd, GlaxoSmithKline, United Therapeutics, Novartis.

R Channick: Consulting fees/honoraria: Actelion Pharmaceuticals Ltd, Bayer HealthCare, United Therapeutics. Steering Com- mittee membership: Actelion Pharmaceuticals Ltd. L Di Scala: Employee Actelion Pharmaceuticals Ltd.

N Galié: Consulting fees/honoraria: Actelion Pharmaceuticals Ltd, Bayer HealthCare, GlaxoSmithKline, Pfizer. Steering Committee membership: Actelion Pharmaceuticals Ltd.

HA Ghofrani: Consulting fees/honoraria: Actelion Pharmaceuticals Ltd, Bayer HealthCare, Gilead Sciences Inc, GlaxoSmithKline, Merck \& Co, Novartis Corporation, Pfizer Inc. Steering Committee membership: Actelion Pharmaceuticals Ltd, Bayer HealthCare, Gilead Sciences Inc, GlaxoSmithKline, Merck \& Co, Novartis Corporation, Pfizer Inc.

MM Hoeper: Consulting fees/honoraria: Actelion Pharmaceuticals Ltd, Bayer HealthCare, GlaxoSmithKline, Pfizer, Gilead Sciences. Steering Committee membership: Actelion Pharmaceuticals Ltd.

I Lang: Consulting fees/honoraria: Actelion Pharmaceuticals Ltd, Bayer HealthCare, GlaxoSmithKline, Novartis Corporation, United Therapeutics. Steering Committee membership: Actelion Pharmaceuticals Ltd.

V McLaughlin: Consulting fees/honoraria: Actelion Pharmaceuticals Ltd, Bayer HealthCare, Gilead Sciences Inc, United Therapeutics, Ikaria, Novartis. Steering Committee membership: Actelion Pharmaceuticals Ltd, Bayer HealthCare, Gilead Sciences Inc, United Therapeutics, Ikaria.

R Preiss: Employee Actelion Pharmaceuticals Ltd. LJ Rubin: Consulting fees/honoraria: Actelion Pharmaceuticals Ltd, Arena Pharmaceuticals, GeNO Pharmaceuticals, Lung Biotechnology, Gilead Sciences Inc, United Therapeutics. Steering Committee membership: Actelion Pharmaceuticals Ltd.

G Simonneau: Consulting fees/honoraria: Actelion Pharmaceuticals Ltd, Bayer HealthCare, Eli Lilly \& Co, GlaxoSmithKline, Novartis Corporation, Pfizer Inc. Steering Committee membership: Actelion Pharmaceuticals Ltd. O Sitbon: Consulting fees/honoraria: Actelion Pharmaceuticals Ltd, Bayer HealthCare, GlaxoSmithKline, Pfizer Inc, United Therapeutics. Steering Committee membership: Actelion Pharmaceuticals Ltd.

\section{S112 LONG-TERM SAFETY AND EFFICACY OF IVACAFTOR IN PEDIATRIC PATIENTS AGED 2-5 YEARS WITH CYSTIC FIBROSIS AND A CFTR GATING MUTATION}

\subsection{6/thoraxjnl-2016-209333.466}

JC Davies has served on advisory boards, undertaken educational activities, and served as national/site principal investigator for trials, for which her institution has received funding from Vertex Pharmaceuticals Incorporated.

$S$ Robertson is an employee of Vertex Pharmaceuticals Incorporated and may own stock or stock options in that company.

J Cooke is an employee of Vertex Pharmaceuticals Incorporated and may own stock or stock options in that company.

M Higgins is an employee of Vertex Pharmaceuticals Incorporated and my own stock or stock options in that company.

M Rosenfeld: has served as a national and site investigator for trials and as a consultant, for which her institution received funding from Vertex Pharmaceuticals Incorporated. 